\title{
A Novel Stability-Indicating Method for the Simultaneous Estimation of Saxagliptin and Dapagliflozin in Rat Serum by Using UV Spectroscopy
}

Raveendra BG*, KumarRA, Shaheen SD, Greeshma A, Satyanarayana M, Manikanta RSHT and Syam CPB

Department of Pharmaceutical Analysis and Quality Assurance, A. K. R. G. College of Pharmacy, Nallajerla, Andhra Pradesh-534112, India

\begin{abstract}
A new approach developed for stability-indicating, simultaneous estimation of Saxagliptin and Dapagliflozin in rat serum by using UV spectroscopy. Saxagliptin detection wave length was at $222 \mathrm{~nm}$ with water is solvent and Dapagliflozin detection wave length was at $274 \mathrm{~nm}$ with phosphate buffer $\mathrm{pH} 6.8$ is solvent. Both drugs are obeyed the beers-lamberts concentration range was founds to be $1-10 \mu \mathrm{g} / \mathrm{mL}$. The present method was optimized and validated in spiked rat serum according to $\mathrm{ICH}$ guidelines. All validation parameters were found to be within the acceptable limits and stability-indicating studies were conducted under different conditions founds in negligible. The present method was simple and sensitive; it was successfully adopted for the simultaneous estimation of Saxagliptin and Dapagliflozin in rat serum samples by using UV spectroscopy.
\end{abstract}

Keywords: Saxagliptin; Dapagliflozin; Serum; Spectroscopic method; Rat

\section{Introduction}

Saxagliptin is chemically called as (1S, $3 \mathrm{~S}, 5 \mathrm{~S})-2-[(2 \mathrm{~S})-2$-Amino-2-(3 hydroxytricyclo [3.3.1.13, 7] dec-1-yl) acetyl]-2-azabicyclo [3.1.0] hexane-3-carbonitrile (Figure 1). It is the oral hypoglycemic (antidiabetic) agent, class of dipeptidyl peptidase (DPP-4) inhibitor [1]. Saxagliptin was inhibiting the activity of dipeptidyl peptidase-4(DPP-4) enzyme by increasing the insulin production in response to meal and decreasing the gluconeogensis rate in the liver, in blood glucose regulation is thought to be through degradation of GIP [2] and the degradation of GLP-1 [3]. Saxagliptin was used for the treatment of type-2 diabetics in the form of mono or combination of with other drugs.

Dapagliflozin is chemically called as (1S)-1, 5-anhydro-1-C-[4chloro-3-[(4-ethoxyphenyl) methyl] phenyl]-D-glucitol (Figure 2). It is a highly selective, sodium-Glucose Co-Transporter 2 (SGLT2). Dapagliflozin blocking the activity of the sodium-glucose transport proteins, which is regulates for at least $90 \%$ of the glucose reabsorption in the kidney and obstructs the transporter mechanism causes blood glucose to be removed through the urine. Dapagliflozin is improved the glyceamic control in patients with type 2 Diabetes Mellitus [4].

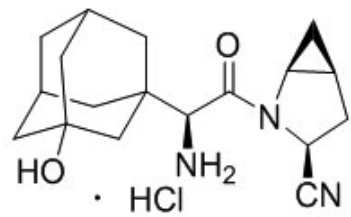

Figure 1: Chemical structure of saxagliptin.

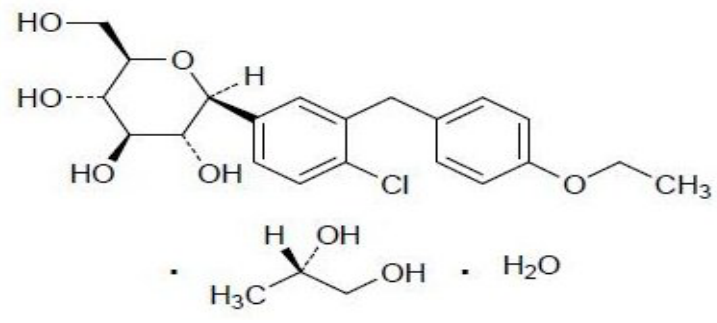

Figure 2: Chemical structure of dapagliflozin.
Few analytical methods based on UV [5-8], RP-HPLC $[9,10]$ and LC-MS/MS [11] for the estimation of saxagliptin and dapagliflozin. Although literature survey reveals that various methods were reported for the saxagliptin and dapagliflozin both for single determination and in combination with other drugs, but no method determination has been reported for the analysis of this combination of these drugs in rat serum. Stability studies were performed under different conditions like acid, base, and oxide, thermal and neutral hydrolysis as per the guidelines of ICH [11]. In this method solvents are aqueous solvents, $\lambda$ max range is lesser and fully validated when compared with previous literature which uses organic solvents, gives higher $\lambda$ max value and incomplete validated data, because the present method was simple, sensitive and more accurate. Serum is extracted by using liquid liquid extraction to inhibit the protein binding to drug molecules before the UV detection. Once extraction is carried out serum proteins are get filtered which do not interfere in UV detection. The present method was simple and sensitive; it was successfully adopted for the simultaneous estimation of saxagliptin and dapagliflozin in rat serum bulk and pharmaceutical dosage form.

\section{Experimental}

\section{Instrument}

ElicoSL164 UV-Visible spectrophotometer with double beam detector configuration. The above instruments had automatic wavelength accuracy $0.1 \mathrm{~nm}$ and matched quartz cells and weighing balance (Elico, India).

*Corresponding author: Raveendra BG, Department of Pharmaceutical Analy sis and Quality Assurance, A. K. R. G. College of Pharmacy, Nallajerla, Andhra Pradesh-534112, India, Tel: + 919030102494; E-mail: upendragudimitla@gmail.com Received February 19, 2018; Accepted March 12, 2018; Published March 20, 2018 Citation: Raveendra BG, KumarRA, Shaheen SD, Greeshma A, Satyanarayana M, et al. (2018) A Novel Stability-Indicating Method for the Simultaneous Estimation of Saxagliptin and Dapagliflozin in Rat Serum by Using UV Spectroscopy. Pharm Anal Acta 9: 579. doi: 10.4172/2153-2435.1000579

Copyright: $\odot 2018$ Raveendra BG, et al. This is an open-access article distributed under the terms of the Creative Commons Attribution License, which permits unrestricted use, distribution, and reproduction in any medium, provided the original author and source are credited. 
Citation: Raveendra BG, KumarRA, Shaheen SD, Greeshma A, Satyanarayana M, et al. (2018) A Novel Stability-Indicating Method for the Simultaneous Estimation of Saxagliptin and Dapagliflozin in Rat Serum by Using UV Spectroscopy. Pharm Anal Acta 9: 579. doi: $10.4172 / 2153-2435.1000579$

Page 2 of 5

\section{Materials}

Blank rat serum, saxagliptin and dapagliflozin were gift samples from Spectrum Pharma Research Solutions, Hyderabad, India. Formulations were procured from local Market, Tanuku, India. All reagents and chemicals used were purchased form Nico chemicals Pvt. Ltd.

\section{Solvent section}

Saxagliptin soluble in water and dapagliflozin soluble in phosphate buffer $\mathrm{pH} 6.8$ were selected for the solvents through the experiment.

\section{Wavelength selection}

Saxagliptin and dapagliflozin working concentration is $10 \mu \mathrm{g} / \mathrm{mL}$ was prepared and scanned UV range $200-400 \mathrm{~nm}$ using a water and phosphate buffer $\mathrm{pH} 6.8$ as a blank. The maximum absorbance shown at $222 \mathrm{~nm}$ for saxagliptin and maximum absorbance shown at $274 \mathrm{~nm}$ for dapagliflozin, respectively. The $\lambda$ maximum graphs of saxagliptin and dapagliflozin were shown in Figures 3 and 4.

\section{Method Development}

\section{Saxagliptin standard preparation}

$100 \mathrm{mg}$ of saxagliptin pure drug was weighed and taken in dry and clean conical flask, and then it will dissolve in $100 \mathrm{ml}$ of water. $10 \mathrm{ml}$ of solution took from stock solution and then made up to $100 \mathrm{ml}$ with water and further dilutions were made to produce the concentration is $10 \mu \mathrm{g} / \mathrm{mL}$.

\section{Dapagliflozin standard preparation}

$100 \mathrm{mg}$ of dapagliflozin pure drug was weighed and taken in dry and clean conical flask then it dissolved in $100 \mathrm{ml}$ of phosphate buffer $\mathrm{pH}$ 6.8. $10 \mathrm{ml}$ of solution took from stock solution and then made up to $100 \mathrm{ml}$ with phosphate buffer $\mathrm{pH} 6.8$ and further dilutions were made to produce the concentration is $10 \mu \mathrm{g} / \mathrm{mL}$.

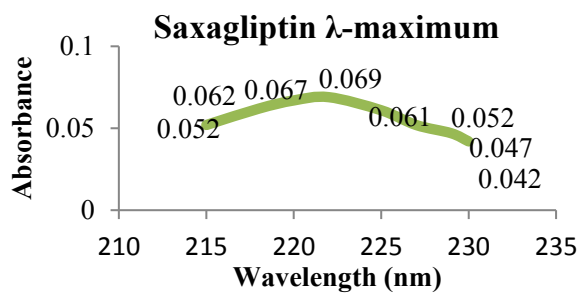

Figure 3: Saxagliptin $\lambda$-maxima.

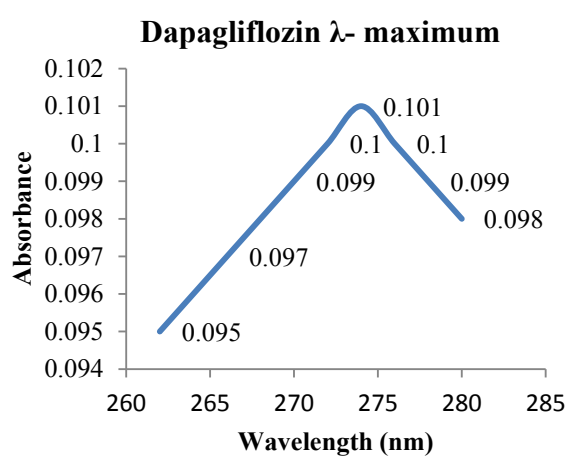

Figure 4: Dapagliflozin $\lambda$-maximum

\section{Preparation of calibration curve of saxagliptin}

A calibration curve was plotted over a concentration range of 1-10 $\mu \mathrm{g} / \mathrm{mL}$ for saxagliptin. Precisely measured standard stock solution of saxagliptin $(1,3,5,7,8,9$ and $10 \mathrm{ml})$ was transferred to a series of 10 $\mathrm{ml}$ volumetric flasks and the volume to each flask was adjusted to $10 \mathrm{ml}$ with water. Calibration curve was prepared by plotting concentration of saxagliptin on $\mathrm{X}$-axis and their respective absorbance's on $\mathrm{Y}$-axis. Calibration data are presented in Table 1.

\section{Preparation of calibration curve of dapagliflozin}

A calibration curve was plotted over a concentration range of 1-10 $\mu \mathrm{g} / \mathrm{mL}$ for dapagliflozin. Precisely measured standard stock solution of dapagliflozin $(1,3,5,7,8,9$ and $10 \mathrm{ml})$ was transferred to a series of 10 $\mathrm{ml}$ volumetric flasks and the volume to each flask was adjusted to 10 $\mathrm{ml}$ with phosphate buffer $\mathrm{pH}$ 6.8. Calibration curve was prepared by plotting concentration of dapagliflozin on $\mathrm{X}$-axis and their respective absorbance's on Y-axis. Calibration data are presented in Table 2.

\section{Method Validation}

The developed method was validated for various parameters like linearity, precision, accuracy, limit of detection, limit of quantitation, robustness and ruggedness according to ICH guidelines.

\section{Linearity}

This manifests linear relationship in the range of $1-10 \mu \mathrm{g} / \mathrm{mL}$ of saxagliptin and dapagliflozin.

\section{Precision}

The intra-day precision analysed in the same day and interday precision analysed for three consecutive days. The results were indicated by calculated per cent relative standard deviation.

\section{Accuracy}

Accuracy was carried out at three different levels $40 \%, 80 \%$ and $120 \%$. The percentage of accuracy was calculated as mean \pm standard deviation.

\begin{tabular}{|c|c|c|}
\hline S. No & $\begin{array}{c}\text { Concentration } \\
(\boldsymbol{\mu} \mathbf{g} / \mathbf{m L})\end{array}$ & Absorbance \\
\hline 0 & 0 & 0.032 \\
\hline 1 & 1 & 0.080 \\
\hline 2 & 3 & 0.192 \\
\hline 3 & 5 & 0.257 \\
\hline 4 & 7 & 0.293 \\
\hline 5 & 8 & 0.338 \\
\hline 6 & 9 & 0.380 \\
\hline
\end{tabular}

Table 1: Calibration data of saxagliptin.

\begin{tabular}{|c|c|c|}
\hline S. No & $\begin{array}{c}\text { Concentration } \\
(\boldsymbol{\mu} \mathbf{g} / \mathbf{m l})\end{array}$ & Absorbance \\
\hline 1 & 1 & 0.038 \\
\hline 2 & 3 & 0.080 \\
\hline 3 & 5 & 0.119 \\
\hline 4 & 7 & 0.163 \\
\hline 5 & 8 & 0.188 \\
\hline 6 & 9 & 0.210 \\
\hline 7 & 10 & 0.230 \\
\hline
\end{tabular}

Table 2: Calibration data of dapagliflozin. 
Citation: Raveendra BG, KumarRA, Shaheen SD, Greeshma A, Satyanarayana M, et al. (2018) A Novel Stability-Indicating Method for the Simultaneous Estimation of Saxagliptin and Dapagliflozin in Rat Serum by Using UV Spectroscopy. Pharm Anal Acta 9: 579. doi: 10.4172/2153-2435.1000579

Page 3 of 5

\section{Limit of detection (LOD)}

Formula for measuring of limit of detection:

$\mathrm{LOD}=3.3 \sigma / \mathrm{S}$

Where,

$\Sigma:$ Standard deviation

S: Slope

\section{Limit of quantification (LOQ)}

Formula for measuring of limit of quantification:

$\mathrm{LOD}=10 \sigma / \mathrm{S}$

Where,

$\Sigma$ : Standard deviation

S: Slope

\section{Stability-indicating studies}

A stability-indicating study was conducted as per ICH Q2 (R1) regulations of both drugs like saxagliptin and dapagliflozin and founds its negligible.

\section{Serum studies}

This manifests linear relationship in the range of $40-84 \mu \mathrm{g} / \mathrm{mL}$ of saxagliptin and dapagliflozin, in spiked rat serum, respectively.

\section{Results and Discussion}

\section{Selection of wavelength}

The spectra of saxagliptin in water showed absorption at $222 \mathrm{~nm}$ shown in Figure 3 and the spectra of dapagliflozin showed in phosphate buffer pH 6.8 absorption at $274 \mathrm{~nm}$ shown in Figure 4, respectively.

\section{Linearity}

The linearity for the proposed method was investigated at seven concentration levels $(1-10 \mu \mathrm{g} / \mathrm{mL})$ of reference standard saxagliptin and dapagliflozin, respectively. The linearity of saxagliptin and dapagliflozin were shown in Tables 1 and 2 and Figures 3 and 4.

\section{Precision}

The percent RSD value of intra-day and inter-day precision were found to be 0.021 and 0.014 for saxagliptin and 0.02 and 0.0128 for dapagliflozin, respectively, as shown in Table 3 . The percentage of RSD values of Saxagliptin and Dapagliflozin was not more than $2 \%$. The value of percentage of RSD is within the limits.

\section{Accuracy}

The percentage of recovery of saxagliptin was found to be $99.01 \%$ and percentage recovery of dapagliflozin was found to be $99.08 \%$ shown in Table 4, respectively. The range of recovery of saxagliptin and dapagliflozin is within the limits.

\section{Limit of detection}

The limit of detection of saxagliptin and dapagliflozin were obtained the values $0.088 \mu \mathrm{g} / \mathrm{mL}$ and $0.197 \mu \mathrm{g} / \mathrm{mL}$ it indicates the high sensitivity of the proposed method, data shown in Table 4.

\section{Limit of quantitation}

The limit of quantitation of saxagliptin and dapagliflozin were obtained the value 0.267 and $0.598 \mu \mathrm{g} / \mathrm{mL}$, it indicates the high sensitivity of the proposed method, data shown in Tables 4 to 6 (Figures 5 and 6).

\section{Stability-indicating studies}

Stability-indicating studies performing like acid, base, oxide and neutral hydrolysis on saxagliptin and dapagliflozin respectively. The percentage of degradation of saxagliptin and dapagliflozin found within the limits.

\begin{tabular}{|c|c|c|c|c|}
\hline $\begin{array}{l}\text { Sample } \\
\text { number }\end{array}$ & $\begin{array}{l}\text { Assay of } \\
\text { saxagliptin }\end{array}$ & $\begin{array}{l}\text { Assay of } \\
\text { saxagliptin }\end{array}$ & $\begin{array}{c}\text { Assay of } \\
\text { dapagliflozin }\end{array}$ & $\begin{array}{c}\text { Assay of } \\
\text { dapagliflozin }\end{array}$ \\
\hline & $\begin{array}{l}\text { Intra-day } \\
\text { precision }\end{array}$ & $\begin{array}{l}\text { Inter-day } \\
\text { precision }\end{array}$ & $\begin{array}{l}\text { Intra-day } \\
\text { precision }\end{array}$ & $\begin{array}{l}\text { Inter-day } \\
\text { precision }\end{array}$ \\
\hline 1 & 97.50 & 97.51 & 98.22 & 98.23 \\
\hline 2 & 97.53 & 97.52 & 98.23 & 98.24 \\
\hline 3 & 97.55 & 97.54 & 98.24 & 98.23 \\
\hline 4 & 97.54 & 97.53 & 98.23 & 98.22 \\
\hline 5 & 97.50 & 97.50 & 98.22 & 98.21 \\
\hline 6 & 97.51 & 97.52 & 98.20 & 98.21 \\
\hline Mean & 97.52 & 97.53 & 98.22 & 98.22 \\
\hline S.D & 0.0210 & 0.0140 & 0.020 & 0.0126 \\
\hline$\%$ RSD & 0.0210 & 0.0140 & 0.020 & 0.0128 \\
\hline
\end{tabular}

Table 3: Precision data of saxagliptin and dapagliflozin.

\begin{tabular}{|c|c|c|c|c|c|}
\hline Drug name & $\begin{array}{c}\text { Level of } \\
\text { addition } \\
(\mathbf{\%})\end{array}$ & $\begin{array}{c}\text { Amount } \\
\text { added } \\
\text { (mg) }\end{array}$ & $\begin{array}{c}\text { Average \% } \\
\text { recovery }\end{array}$ & $\begin{array}{c}\text { Drug found } \\
\text { (mg/mL) }\end{array}$ & 99.75 \\
\hline saxagliptin & 40 & 4 & 3.99 & 98.62 \\
\hline & 80 & 8 & 7.89 & 98.66 \\
\hline & 120 & 12 & 11.84 & $99.01 \pm 0.0143$ \\
\hline & 40 & 4 & 3.97 & 99.25 \\
\hline & 80 & 8 & 7.82 & 97.75 \\
\hline
\end{tabular}

Table 4: Accuracy data of saxagliptin and dapagliflozin. 
Citation: Raveendra BG, KumarRA, Shaheen SD, Greeshma A, Satyanarayana M, et al. (2018) A Novel Stability-Indicating Method for the Simultaneous Estimation of Saxagliptin and Dapagliflozin in Rat Serum by Using UV Spectroscopy. Pharm Anal Acta 9: 579. doi: $10.4172 / 2153-2435.1000579$

Page 4 of 5

\begin{tabular}{|c|c|c|c|}
\hline S. No & Parameter & Saxagliptin & Dapagliflozin \\
\hline 1 & Absorption maxima $(\mathrm{nm})$ & 222 & 274 \\
\hline 2 & Linearity $(\mathrm{mcg} / \mathrm{ml})$ & $1-10$ & $1-10$ \\
\hline 3 & Standard regression equation & $Y=0.0374 x$ & $Y=0.0234 x$ \\
\hline 4 & Correlation coefficient $\left(\mathrm{r}^{2}\right)$ & 0.9989 & 0.9932 \\
\hline 5 & Molar extinction coefficient & 0.0123 & 0.0116 \\
\hline 6 & $\begin{array}{c}\text { Accuracy } \\
(\% \text { recovery } \pm \text { SD })\end{array}$ & $99.01 \pm 0.0143$ & $99.08 \pm 0.025$ \\
\hline 7 & Precision & $\begin{array}{c}97.52 \% \\
\text { (Intra-day precision) } \\
\text { and } \\
97.53 \% \\
\text { (Inter-day precision) }\end{array}$ & $\begin{array}{c}98.22 \% \\
\text { (Intra-day precision) } \\
\text { and } \\
98.28 \% \\
\text { (Inter-day precision) }\end{array}$ \\
\hline 8 & $\begin{array}{c}\text { Sandell's sensitivity } \\
\text { (mg/cm 2/0.001 } \\
\text { absorbance unit) }\end{array}$ & 0.0813 & 0.0862 \\
\hline 9 & LOD $(\mu \mathrm{g} / \mathrm{mL})$ & 0.088 & 0.197 \\
\hline 10 & $\mathrm{LOQ}(\mu \mathrm{g} / \mathrm{mL})$ & 0.267 & 0.598 \\
\hline
\end{tabular}

Table 5: Validation parameters of saxagliptin and dapagliflozin.

\begin{tabular}{|c|c|c|c|c|c|c|}
\hline Drug name & $\begin{array}{l}\text { Type of stress } \\
\text { conditions }\end{array}$ & $\begin{array}{l}\text { Amount of } \\
\text { drug to be } \\
\text { taken (mg) }\end{array}$ & $\begin{array}{l}\text { Amount of } \\
\text { solution } \\
\text { taken } \\
(\mu \mathrm{g} / \mathrm{mL})\end{array}$ & $\begin{array}{c}\text { Test } \\
\text { absorbance }\end{array}$ & $\begin{array}{c}\text { Standard } \\
\text { absorbance }\end{array}$ & $\begin{array}{c}\% \\
\text { Degradable }\end{array}$ \\
\hline \multirow[t]{4}{*}{ Saxagliptin } & Acidic conditions & 10 & 1 & 0.422 & 0.123 & 97.09 \\
\hline & Basic conditions & 10 & 1 & 0.117 & 0.123 & 89.05 \\
\hline & Oxidation condition & 10 & 1 & 0.921 & 0.123 & 98.67 \\
\hline & Neutral condition & 10 & 1 & 0.130 & 0.123 & 90.54 \\
\hline \multirow[t]{4}{*}{ Dapagliflozin } & Acidic conditions & 10 & 1 & 0.048 & 0.116 & 75.90 \\
\hline & Basic conditions & 10 & 1 & 0.064 & 0.116 & 81.90 \\
\hline & Oxidation condition & 10 & 1 & 0.095 & 0.116 & 87.80 \\
\hline & Neutral condition & 10 & 1 & 0.033 & 0.116 & 64.90 \\
\hline
\end{tabular}

Table 6: Stability-indicating data of saxagliptin and dapagliflozin.

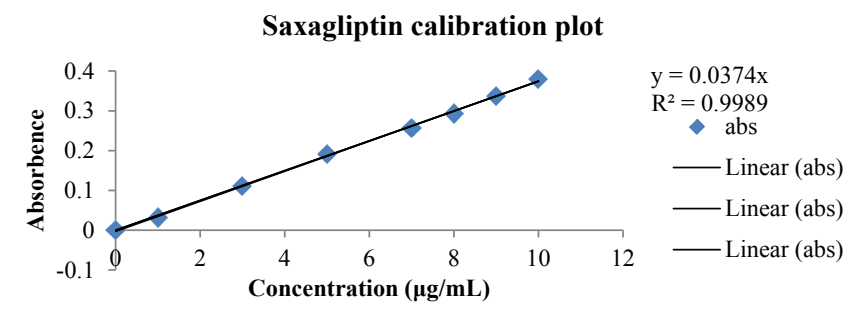

Figure 5: Saxagliptin calibration plot.

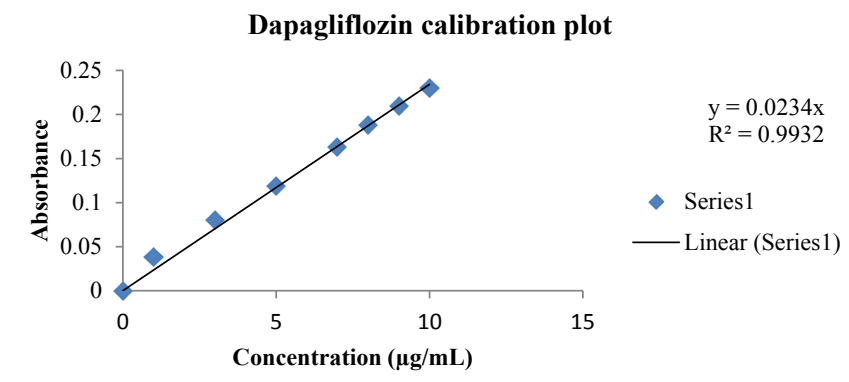

Figure 6: Dapagliflozin calibration plot.

\section{Serum Studies}

\section{Estimation of saxagliptin in spiked rat serum}

Calibration plot: The manifest of calibration plot in the range of $40-84 \mu \mathrm{g} / \mathrm{ml}$ of saxagliptin shown in Figure 7 and Table 7.
Saxagliptin calibration plot in rat serum

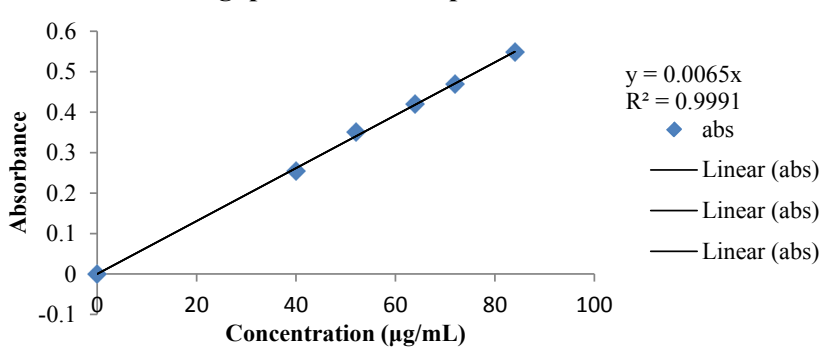

Figure 7: Saxagliptin calibration plot in spiked rat serum.

\begin{tabular}{|c|c|c|}
\hline S. No & Concentration $(\boldsymbol{\mu g} / \mathbf{m L})$ & Absorbance \\
\hline 1 & 40 & 0.254 \\
\hline 2 & 52 & 0.350 \\
\hline 3 & 64 & 0.420 \\
\hline 4 & 72 & 0.469 \\
\hline 5 & 84 & 0.548 \\
\hline
\end{tabular}

Table 7: Saxagliptin calibration data in spiked rat serum.

\section{Estimation of dapagliflozin in spiked rat serum}

Calibration plot: The manifest of calibration plot in the range of 40-84 $\mu \mathrm{g} / \mathrm{ml}$ of dapagliflozin shown in Figure 8 and Table 8.

\section{Conclusion}

A simple, sensitive and appreciable stability-indicating simultaneous 
Citation: Raveendra BG, KumarRA, Shaheen SD, Greeshma A, Satyanarayana M, et al. (2018) A Novel Stability-Indicating Method for the Simultaneous Estimation of Saxagliptin and Dapagliflozin in Rat Serum by Using UV Spectroscopy. Pharm Anal Acta 9: 579. doi: $10.4172 / 2153-2435.1000579$

Page 5 of 5

\begin{tabular}{|c|c|c|}
\hline S. No & Concentration $(\boldsymbol{\mu g} / \mathbf{m L})$ & Absorbance \\
\hline 1 & 40 & 0.140 \\
\hline 2 & 52 & 0.185 \\
\hline 3 & 64 & 0.232 \\
\hline 4 & 72 & 0.271 \\
\hline 5 & 84 & 0.318 \\
\hline
\end{tabular}

Table 8: Dapagliflozin calibration data in spiked rat serum.

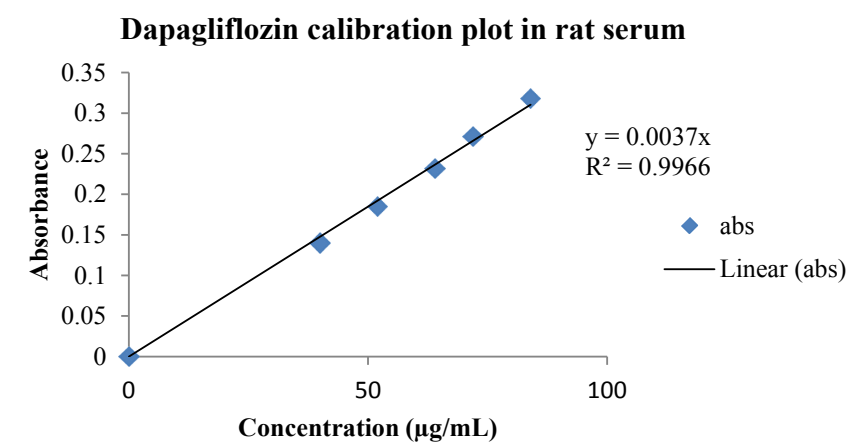

Figure 8: Dapagliflozin calibration plot in spiked rat serum.

estimation of saxagliptin and dapagliflozin in spiked rat serum is by using UV spectroscopy. The method was fast and economical and it was also selective and sensitive to the desirable range. The results of the analysis were validated as per ICH guidelines and by recovery studies. The stabilityindicating nature of the proposed method was established by performing forced degradation, which provided degradation behaviour of saxagliptin and dapagliflozin under various conditions. In vitro rat studies were conducted in spiked rat serum with saxagliptin and dapagliflozin by using UV spectroscopy. It will help to improve the sensitivity of the method in future works on saxagliptin and dapagliflozin.

\section{References}

1. Deacon CF, Holst JJ (2009) Saxagliptin is a new dipeptidyl peptidase-4 inhibitor for the treatment of type 2 diabetes. Adv Ther 26: 488-499.

2. Mentlein R, Gallwitz B, Schmidt WE (1993) Dipeptidyl-peptidase IV hydrolyses gastric inhibitory polypeptide, glucagon-like peptide-1(7-36) amide, peptide histidine methionine and is responsible for their degradation in human serum. Eur J Biochem 214: 829-835.

3. Ahren B, Landin-Olsson M, Jansson PA, Svensson M, Holmes D, et al. (2004) Inhibition of dipeptidyl peptides-4 reduces glycemia, sustains insulin levels and reduces glucagon levels in the type 2 diabetes. J Clin Endocrinol Metab 89: 2078-2084.

4. Vithoba MG, Krishna RG, Hemke AT (2017) Estimation of dapagliflozin from its tablet formulation by UV-spectrophotometry. Pharm Methods 8: 102-107.

5. Jeyabalan G, Narendra N (2012) Analytical method development and validation of saxagliptine a novel dipeptidyl peptidase iv inhibitors in pure and tablet dosage form by UV-Vis spectroscopy. IJIPLS 2: 145-150.

6. Sanjeev VD, Madhumita AR, Shubhangi CD (2016) Development and validation of UV spetrophotometric method for estimation of saxagliptin in bulk and pharmaceutical dosage form. IJPD 4: 30-34.

7. Karuna PC, Eswaraiah MC, Rao BMV (2015) Unique UV spectrophotometric method for reckoning of dapagliflozin in bulk and pharmaceutical dosage forms. Journal of Chemical and Pharmaceutical Research 7: 45-49.

8. Sarada B, Reddy K, Kumar BD (2017) Method development and validation of pioglitazone and saxagliptin by RP-HPLC. IJRPB 5: 44-46.

9. Manasa S, Lakshmi KD, Nagarjuna RG, Sreenivasa S (2014) Development and validation of stability-indicating RP-HPLC method for determination of dapagliflozin. JAPER 4: 350-353.

10. Xs X, Demers R, Christopher J, Su H, Cojocaru L, et al. (2012) Liquid chromatography and tandem mass spectrometry method for the quantitative determination of saxagliptin and its major pharmacologically active 5-monohydroxy metabolite in human plasma method validation and overcoming specific and non-specific binding at low concentrations. J Chromatogr B Analyt Technol Biomed Life Sci 889: 77-86.

11. ICH Harmonised Tripartite Guideline, validation of analytical procedures: Text methodology, Q2 (R1) (2005). International Conference on Harmonization, Geneva, pp: 1-13. 